\title{
Oral squamous cell carcinoma proliferative phenotype is modulated by proanthocyanidins: a potential prevention and treatment alternative for oral cancer Michael King, Kourt Chatelain, Dustin Farris, Dayne Jensen, Jason Pickup, Aaron Swapp, Susan $\mathrm{O}^{\prime}$ Malley ${ }^{\dagger}$ and Karl Kingsley*†
}

Address: Department of Biomedical Sciences, School of Dental Medicine, University of Nevada, Las Vegas, USA

Email: Michael King - michael.king@sdm.unlv.edu; Kourt Chatelain - kourt.chatelain@sdm.unlv.edu;

Dustin Farris - dustin.farris@sdm.unlv.edu; Dayne Jensen - dayne.jensen@sdm.unlv.edu; Jason Pickup - jason.pickup@sdm.unlv.edu;

Aaron Swapp - aaron.swapp@sdm.unlv.edu; Susan O'Malley - susan.omalley@unlv.edu; Karl Kingsley* - karl.kingsley@unlv.edu

* Corresponding author †Equal contributors

Published: 19 June 2007

BMC Complementary and Alternative Medicine 2007, 7:22 doi:10.1 186/1472-6882-7-22
Received: 9 February 2007

Accepted: 19 June 2007

This article is available from: http://www.biomedcentral.com/1472-6882/7/22

(c) 2007 King et al; licensee BioMed Central Ltd.

This is an Open Access article distributed under the terms of the Creative Commons Attribution License (http://creativecommons.org/licenses/by/2.0), which permits unrestricted use, distribution, and reproduction in any medium, provided the original work is properly cited.

\begin{abstract}
Background: Despite the recently reported drop in the overall death rate from cancer, the estimated survival rate and number of deaths from oral cancer remain virtually unchanged. Early detection efforts, in combination with strategies for prevention and risk-reduction, have the potential to dramatically improve clinical outcomes. The identification of non-toxic, effective treatments, including complementary and alternative therapies, is critical if the survival rate is to be improved. Epidemiologic studies have suggested a protective effect from certain plant-derived foods and extracts; however, it has been difficult to isolate and identify the compounds most responsible for these observations. The primary purpose of this study was to investigate the response of human oral squamous cell carcinoma (OSCC) to proanthocyanidin (PAC), a plantderived compound that may inhibit the progression of several other cancers.
\end{abstract}

Methods: Using a series of in vitro assays, we sought to quantify the effects of PAC on OSCC, cervical carcinoma, and non-cancerous cell lines, specifically the effects of PAC on cell proliferation. Recent data suggest that infection with the human papillomavirus (HPV) may also modulate the proliferative potential of OSCC; therefore, we also measured the effects of PAC administration on HPV-transfected OSCC proliferation.

Results: Our results demonstrated that PAC administration was sufficient to significantly suppress cellular proliferation of OSCC in a dose-dependent manner. In addition, the increased proliferation of OSCC after transfection with HPV 16 was reduced by the administration of PAC, as was the proliferation of the cervical cancer and non-cancerous cell lines tested. Our results also provide preliminary evidence that PAC administration may induce apoptosis in cervical and oral cancer cell lines, while acting merely to suppress proliferation of the normal cell line control.

Conclusion: These results signify that PAC may be a compelling candidate for testing in both animal and human models. Furthermore, these data provide adequate justification for elucidating the divergent mechanisms of PAC-induced proliferation, inhibition, and apoptosis among these and other cell lines. 


\section{Background}

More than 30,000 people are diagnosed with oral cancer annually in the United States, and due to a poor survival rate that has remained relatively static, of those who are diagnosed, approximately 7,500 die of this disease each year [1]. Many of these patients will subsequently develop regional tumors, as a result of spreading of the disease to other organs and lymph nodes [2].

Risk factors are anything that significantly increases the chance of a person developing a disease, such as oral cancer. Scientists now agree that the use of tobacco and alcohol, human papillomavirus (HPV) infection, and in the case of lip cancers, exposure to ultraviolet light, are risk factors that increase the likelihood of developing oral cancers [3]. Thus, many oral cancers are believed to have a multifactorial etiology in which environmental and genetic cofactors influence the development and progression of the disease. Recent evidence suggests that among these factors, nutrition may play an important role in retarding the development and progression of oral cancers $[4,5]$. A recent meta-analysis examining the association between fruit and vegetable consumption and the incidence of oral cancer, found a nearly $50 \%$ reduction in oral cancer risk for each additional portion of fruit or vegetable consumed per day [6].

It is generally accepted that fruit and vegetable intake may be correlated with a reduction in the incidence of oral cancers even among tobacco and alcohol users. The knowledge gained thus far, however, does not provide enough specific detail upon which to base effective or comprehensive nutrition or dietary intervention recommendations. More detailed information is needed to identify the active components of fruits and vegetables, to evaluate doseresponse relationships, and to adjust for potential confounders. The stratification of these studies, for example, has revealed that citrus fruit consumption was associated with a larger protective effect against oral cancer than overall fruit consumption, and was greater than green- or overall vegetable consumption [6].

Based upon these and other observations, a growing interest has been developing in alternative and complementary medicine to identify botanical and dietary components for their chemopreventive and chemotherapeutic potential. One such class of compounds, the proanthocyanidins (PACs), are polyphenolic compounds that are highly concentrated in certain dietary fruits and nuts, such as grapes, blueberries, cranberries, and almonds, as well as cacao beans and chocolate [7-10].

PACs belong to a larger class of abundant, plant-derived compounds, flavonoids, which appear to provide many beneficial health effects, largely due to their antioxidant properties. PACs have been shown to protect against oxidative stress and tobacco-induced DNA damage, and to exhibit selective cytotoxicity against some human cancers, including breast, lung, prostate, and gastric carcinomas [11-15]. Extracts from grape peels, grape seeds, and black raspberries, sources that contain high concentrations of PAC, have demonstrated selective suppression of tumorigenic phenotypes in oral cancers, specifically in oral squamous cell carcinomas (OSCC) [16,17].

The possible mechanisms of PACs effects on tumor proliferation are complex and are likely to involve multiple pathways, which may differ according to the type of cancer. For example, PAC derived from grape seed, green tea, and lowbush blueberry, exhibited broad, anti-proliferative properties against multiple cell lines, including colon [18], prostate [14,19-21], breast [22,23], and oral cancers [24]. Grape seed extract (GSE), a rich source of proanthocyanidin, was found to be a potent inhibitor of aromatase activity, an enzyme expressed in higher levels in cancerous than in normal breast tissues [23]. GSE also induced apoptosis of MCF-7 and MDA-MB-235 breast cancer cells through modulation of both Bcl-2 and MEK/ ERK signalling pathways [22]. GSE and other flavonoid extracts were also found to induce apoptosis in colon, leukemia, and oral cancer cell lines via caspase-3 activation $[15,18,24]$, and were reported to inhibit ornithine decarboxylase (ODC), an enzyme involved in epithelial tumor cell proliferation $[13,25,26]$.

To further evaluate the potential relationship between oral cancer inhibition and PAC, we sought to identify any specific or dose-dependent effects that may exist between the administration of GSE-derived PAC and the proliferation of oral cancers. In this way, we hope to more definitively characterize the effects of this non-toxic agent for its chemopreventive or chemotherapeutic value. Quantitative and dose-dependent relationships between PAC administration and oral cancer proliferation could, therefore, be established prior to the identification and elucidation of the pathways involved, and prior to animal and in vivo studies of this compound.

Based upon the observation that flavonoid-rich extracts, including PAC, inhibited proliferation of multiple tumor cell lines, this study examined the potential for PAC to modulate the proliferative phenotype of OSCC in vitro. While the aforementioned studies have increased our understanding of flavonoid- and nutrition-based inhibition of oral cancer proliferation, none to date have adequately investigated the role of PAC in modulating the proliferative phenotype of OSCC. This study tested the hypothesis that PAC modulates, in a dose-dependent manner, the proliferative phenotype of OSCC in vitro. 
We determined that PAC significantly reduced the proliferation of the OSCC cell line, CAL 27, in vitro. Furthermore, this inhibition was dose-dependent and was more pronounced in this oral cancer cell line than in either of the cervical cancer cell lines that we evaluated, Ca Ski and GH354. In addition, the maximal growth inhibitory concentration $\left(\mathrm{GI}_{\mathrm{MAX}}\right)$ of PAC was sufficient to induce a net loss of cells (cytotoxic) in CAL 27, but not in either Ca Ski or GH354 cell lines.

Our previous work established that infection of OSCC with high-risk HPV 16 strongly promoted the proliferative potential of OSCC in vitro [27]. Therefore, we further sought to determine if PAC was capable of modulating HPV-driven OSCC proliferation in vitro. Our results provide one of the first demonstrations of HPV modulating the OSCC proliferative response to PAC. We also found that PAC inhibited HPV-positive OSCC proliferation and that the inhibitory concentration of PAC, providing the maximal proliferation inhibition and cytotoxicity $\left(\mathrm{GI}_{\mathrm{MAX}}\right)$, was the same for both HPV-positive and HPVnegative OSCC. These results suggest that PAC may exhibit selective inhibition of OSCC proliferation and that PAC administration may be sufficient to inhibit the increased proliferation of OSCC in the presence of HPV 16.

Standard chemotherapies and radiation treatment, frequently used to treat oral cancer patients, often have harsh and severe side effects that include tissue damage and malfunction. The discovery and validation of novel treatments and prevention strategies, lacking these harmful side effects, is one of our main short-term goals. This report provides evidence that PAC may provide one possible complementary or alternative therapy for oral cancer patients, as a safe, effective, cost-saving, and non-toxic treatment. We propose that this study provides compelling in vitro data to justify the exploration and elucidation of the mechanisms of PAC-induced proliferation inhibition of oral cancers and for testing of PAC in animal models.

\section{Methods \\ Materials}

Grape seed proanthocyanidin (PAC) extract (Lot \#3717HF7361) was obtained from GNC Preventive Nutrition $^{\circledast}$ (Pittsburgh, PA). This commercial source of PAC was extracted from U.S. grown wine grapes, Vitus vinifera. Such commercial sources of grape seed PAC extract are demonstrated to contain 95\% PAC and contain approximately 80-90\% oligomeric PACs, including dimers, trimers, tetramers, and a small amount of monomeric flavonoids $[28,29]$.

\section{Cell lines and cell culture}

Human oral squamous cell carcinoma (OSCC) CAL 27, human cervical carcinoma (CC) Ca Ski, human cervical adenocarcinoma (CAC) GH354, and human foreskin fibroblasts (hFF) Hs27 cell lines were obtained from American Type Culture Collection (ATCC: Manassas, VA). CAL 27, GH354, and Hs27 cells were maintained in Dulbecco's Modified Eagle's Medium (DMEM) with $4.0 \mathrm{mM}$ L-glutamine adjusted to contain $3.7 \mathrm{~g} / \mathrm{L}$ sodium bicarbonate, $4.5 \mathrm{~g} / \mathrm{L}$ glucose, and $110 \mathrm{mg} / \mathrm{L}$ sodium pyruvate, obtained from HyClone (Logan, UT). Ca Ski cells were maintained in RPMI-1640 medium with $2 \mathrm{mM} \mathrm{L}$ glutamine, adjusted to contain $1.5 \mathrm{~g} / \mathrm{L}$ sodium bicarbonate, $4.5 \mathrm{~g} / \mathrm{L}$ glucose, $10 \mathrm{mM}$ HEPES, and $1.0 \mathrm{mM}$ sodium pyruvate, obtained from ATCC. Media was supplemented with $1 \%$ Penicillin $(10,000$ units/mL)-Streptomycin $(10,000 \mu \mathrm{g} / \mathrm{mL})$ solution and 10\% fetal bovine serum (FBS), obtained from HyClone, except that GH354 was supplemented with 20\% FBS. Cells were cultured in 75 $\mathrm{cm}^{2} \mathrm{BD}$ Falcon tissue-culture treated flasks (Bedford, MA) at $37^{\circ} \mathrm{C}$ and $5 \% \mathrm{CO}_{2}$ in humidified chambers.

\section{Transfection}

CAL 27 cells were seeded in $25 \mathrm{~cm}^{2}$ BD Falcon tissue-culture treated flasks in appropriate media as described above and allowed to achieve $70 \%$ confluence. Cells were then transiently transfected by adding $1 \mu \mathrm{g} / \mathrm{mL}$ of the fulllength HPV type 16 virus, cloned into the pBluescript SKvector (ATCC \#45113). The transfection was performed using the Stratagene Mammalian Transfection Kit (La Jolla, CA) according to the manufacturer's recommended protocol for $\mathrm{CaPO}_{4}$ transfection, and as previously described [27]. Transfected CAL 27 cells (CAL 27-TF16) were maintained in the same cell culture conditions as described above for non-transfected CAL 27 cells. Mock transfectants of CAL 27 (CAL 27-mTF) were also established by performing the transfection protocol, but without using virus.

\section{Microscopy of cell morphology and viability}

Cells were visualized with a Zeiss Axiovert 40 inverted microscope (Gottingen, Germany), and images were captured at $100 \times$ magnification with a Canon PowerShot G6 digital camera (Tokyo, Japan). Digital images were subsequently processed using Adobe Photoshop (San Jose, CA) Image Analysis tools. In brief, several wells of unstained Ca Ski, GH354, CAL 27, CAL 27-TF16, and Hs27 cells were photographed at each time point of the proliferation assays (day 1 - day 4) and at each concentration of PAC $(0-100 \mu \mathrm{g} / \mathrm{mL})$ to visualize any effects on cell morphology. In addition, several wells of cells were also fixed at these time points using $50 \mu \mathrm{L}$ of $10 \%$ buffered formalin and subsequently stained using crystal violet $1 \%$ aqueous solution (Fisher Scientific: Fair Lawn, NJ) to quantitatively document cell morphology, percent of cell spreading, and 
confluence. Additionally, at each time point, several wells were stained using Trypan Blue (Sigma: St. Louis, MO) and live cells were enumerated to determine viability, as previously described $[30,31]$.

\section{Proliferation}

In vitro proliferation assays of CAL 27, CAL 27-mTF, CAL 27-TF16, Ca Ski, GH354, and Hs27 cells were performed in the appropriate complete media, with and without the addition of PAC. The total concentrations of PAC used were between 10 and $100 \mu \mathrm{g} / \mathrm{mL}$. Cells were plated in Corning Costar 96-well assay plates (Corning, NY) at a density of $1.2 \times 10^{4}$ cells per well, maintained at $37^{\circ} \mathrm{C}$ and $5 \% \mathrm{CO}_{2}$ in humidified chambers, and their proliferation was measured over four days. Cultured cells were fixed every 24 hrs (day 1 - day 4) using $50 \mu \mathrm{L}$ of $10 \%$ buffered formalin, and were stained using crystal violet $1 \%$ aqueous solution. The relative absorbance was measured at $630 \mathrm{~nm}$ using a Bio-Tek ELx808 microplate reader (Winooski, VT). Data were analyzed and graphed using Microsoft Excel (Redmond, WA). Three separate, independent replications of each experiment were performed.

\section{Statistics}

The differences between treatments were measured using a $t$ distribution, $\alpha=.05$. All samples were analyzed using two-tailed $t$ tests as departure from normality can make more of a difference in a one-tailed than in a two-tailed $t$ test. As long as the sample size is even moderate (>20) for each group, quite severe departures from normality make little practical difference in the conclusions reached from these analyses [32].

\section{RT-PCR}

RNA was isolated from $1.5 \times 10^{7}$ cells of CAL 27, CAL 27mTF, and CAL 27-TF16, using ABgene Total RNA Isolation Reagent (Epsom, Surrey, UK) and the procedure recommended by the manufacture. RT-PCR was performed with the ABgene Reverse-iT One-Step RT-PCR Kit (ReadyMix Version) and a Mastercycler gradient thermocycler (Eppendorf: Hamburg, Germany) using the following primers synthesized by SeqWright (Houston, TX): HPV16 forward primer, ATGTTTCAGGACCCACAGGA; HPV16 reverse primer, CCTCACGTCGCAGTAACTGT. One $\mu \mathrm{g}$ of template RNA was used for each reaction. The reverse tran-
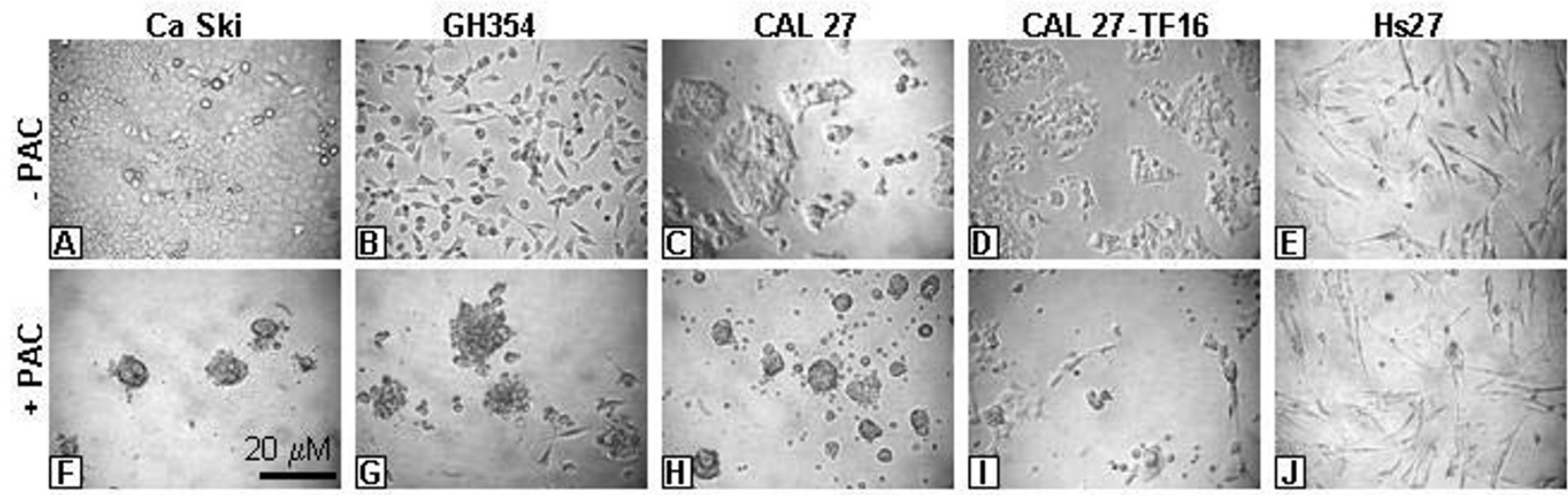

\section{Figure I}

PAC-induced effects on cell morphology in vitro. Cell lines were cultured in the absence (A-E) or presence (F-J) of PAC $(50 \mu \mathrm{g} / \mathrm{mL})$. Ca Ski $(A, F)$ and $\mathrm{GH} 354(\mathrm{~B}, \mathrm{G})$ cervical cancers increased in absolute number and ratio of cell spreading without PAC (A,B) but displayed morphological features characteristic of apoptosis under PAC treatment (F,G). CAL $27(C, H)$ and HPV 16-transfected CAL 27 cells (D,I) also grew in the absence of PAC (C,D), but demonstrated surface blebbing activity and morphological changes similar to cervical cells under PAC treatment $(\mathrm{H}, \mathrm{I})$. Hs 27 normal fibroblast controls (E,J) grew in the absence of PAC (E) and less rapidly in the presence of PAC (J), without demonstrable microscopic evidence of apoptotic cellular features. 
scription step ran for $30 \mathrm{~min}$ at $47^{\circ} \mathrm{C}$, followed by denaturation for $2 \mathrm{~min}$ at $94^{\circ} \mathrm{C}$. Thirty-five amplification cycles were run, consisting of $20 \mathrm{sec}$ denaturation at $94^{\circ} \mathrm{C}$, $30 \mathrm{sec}$ of annealing at $58^{\circ} \mathrm{C}$, and $6.5 \mathrm{~min}$ of extension at $72^{\circ} \mathrm{C}$. Final extension was run for $5 \mathrm{~min}$ at $72^{\circ} \mathrm{C}$. Reaction products were separated by gel electrophoresis using Reliant 4\% agarose gels (Cambrex: Rockland, ME). Bands were visualized by UV illumination of ethidium-bromidestained gels and captured using a Kodak Gel Logic 100 Imaging System and 1D Image Analysis Software (Eastman Kodak: Rochester, NY).

\section{DNA isolation}

DNA was isolated from $1.5 \times 10^{7}$ CAL 27 and CAL 27TF16 cells, cultured with and without PAC, with the GenomicPrep DNA isolation kit (Amersham Biosciences: Buckinghamshire, UK), using the procedure recommended by the manufacturer. DNA was separated by gel electrophoresis using Cambrex Reliant 1\% agarose gels and the bands were visualized by UV illumination of ethidium-bromide-stained gels and captured using a Kodak Gel Logic 100 Imaging System and 1D Image Analysis Software.

\section{Results \\ Cell morphology}

To examine any anti-cancer properties of grape seedderived PAC on oral cancers, we began these experiments with a series of in vitro cell culture experiments designed to identify morphologic or culture-based effects of PAC,

Table I: PAC-induced effects on cell viability, cell spreading, and confluence

\begin{tabular}{lccc}
\hline & $\begin{array}{c}\text { - PAC } \\
{[\mathbf{0} \boldsymbol{\mu} \mathbf{g} \mathbf{m} \mathbf{l}]}\end{array}$ & $\begin{array}{c}\text { + PAC } \\
{[\mathbf{5 0} \boldsymbol{\mu} \mathbf{g} / \mathbf{m l}]}\end{array}$ & $\%$ change \\
\hline Cell viability (\%) & & & \\
Ca Ski & 98 & 10 & -88 \\
GH354 & 96 & 15 & -81 \\
CAL 27 & 81 & 10 & -71 \\
CAL 27-TFI6 & 95 & 27 & -68 \\
Hs27 & 99 & 73 & -26 \\
\hline Cell spreading (\%) & & & \\
Ca Ski & 99 & 5 & -94 \\
GH354 & 63 & 5 & -58 \\
CAL 27 & 85 & 5 & -80 \\
CAL 27-TFI6 & 98 & 10 & -88 \\
Hs27 & 73 & 68 & -5 \\
\hline Confluence (\%) & & & \\
Ca Ski & & & \\
GH354 & 88 & 23 & -74 \\
CAL 27 & 50 & 26 & -48 \\
CAL 27-TFI6 & 45 & 15 & -67 \\
Hs27 & 51 & 11 & -78 \\
& 56 & 25 & -55 \\
\hline
\end{tabular}

first on Ca Ski and GH354 cervical cancer cell lines, and subsequently on CAL 27 and HPV 16-transfected CAL 27 OSCC cell lines, as well as Hs27 normal human foreskin fibroblast cell line controls (Fig. 1). We utilized PAC working concentrations of 10,50 , and $100 \mu \mathrm{g} / \mathrm{mL}$, similar to the concentrations used in other flavonoid- and GSEbased assays of oral cancer proliferation $[17,24]$.

Our results demonstrated that both human cervical carcinoma lines, Ca Ski and GH354 (Fig. 1A, 1B), exhibited PAC-related changes in cell shape and cell structure at each concentration of PAC indicative of apoptotic changes, although these effects were most pronounced at $50 \mu \mathrm{g} / \mathrm{mL}$ (Fig. 1F, 1G). Cells rounded together and were characterized by substantial cell-surface blebbing, typical features of epithelial cancers undergoing morphological alterations associated with apoptosis [5]. Many of these cervical cancer cells further demonstrated the apparent rupturing of blisters, generating the appearance of a swollen, granular version of the original cells. In addition, there was a proportional reduction in the number of cells, the percent of spreading, and cell viability with the increased dose of PAC (Table 1).

An examination of the OSCC cell line, CAL 27, revealed PAC-related changes in morphology that paralleled the changes that were observed for both cervical cancer cell lines (Fig. 1C, 1H). The overwhelming majority of attached, spreading cells that were seen in the control were absent in the PAC experimental wells, with most PAC-treated cells exhibiting an apoptosis-like morphology, including rounded clustering of cells with surface blebbing and bubbling. In addition, many cells appeared to be detaching from the growth substrate or were found as floating cells which could be recovered from the culture medium. PAC also demonstrated reduction in the number, spreading, and viability of CAL 27 cells observed in each assay (Table 1).

Our previous work with CAL 27 demonstrated that transfection with HPV 16 increased the proliferation and induced the spreading of these cells, even when plated at low density [27]. In this study, CAL 27-TF16 cells (Fig. 1D) demonstrated a more heterogeneous mixture of cellular morphologies in the presence of PAC (Fig. 1I) than was observed for non-transfected CAL 27. Some CAL 27TF16 cells retained typical spreading, adherent morphologies, while a smaller proportion of cells exhibited morphologies characteristic of the initial stages of apoptosis. These early stage-specific features included smaller groupings of rounding, clustering cells, cell-surface microspikes, and blebbing. A less pronounced reduction in cell spreading and cell viability was observed for CAL 27-TF16 (Table 1). 


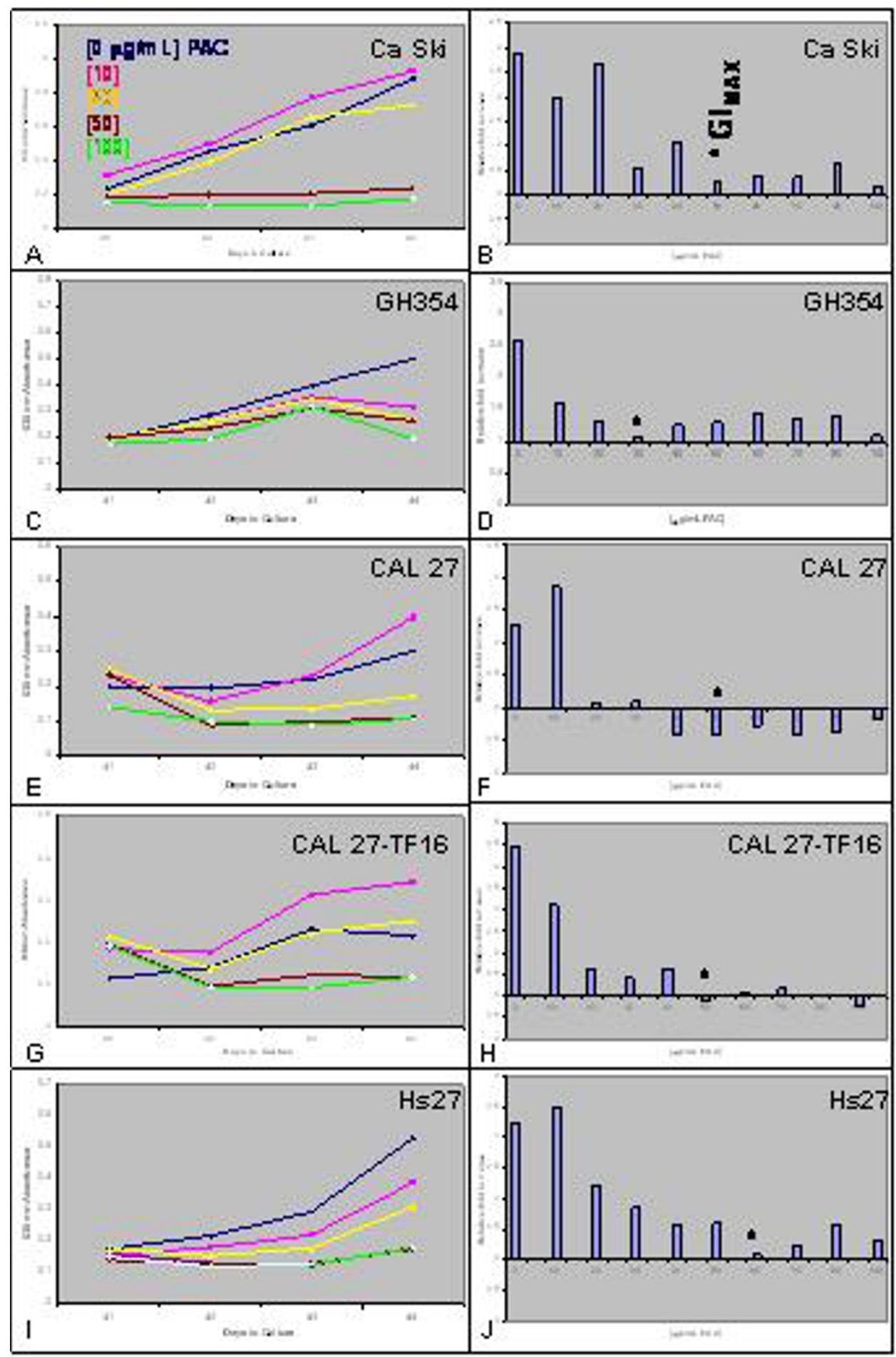

Figure 2

PAC-induced effects on cell proliferation in vitro. 96-well assay plates with media containing $10 \%$ fetal bovine serum (FBS) in the absence and presence of increasing PAC dosages [0-100 $\mu \mathrm{g} / \mathrm{mL}]$ and cells were allowed to proliferate for four days. The addition of PAC at low concentration $(10 \mu \mathrm{g} / \mathrm{mL})$ stimulated proliferation of Ca Ski (A), CAL 27 (E) and CAL 27TFI6 (G) cells, but inhibited proliferation of GH354 (C) and Hs27 (I) cells. Measurement of the relative change in proliferation between day 4 and day I revealed that the maximal PAC growth inhibition dose $\left(\mathrm{GI}_{\mathrm{MAX}}\right)$ was between $30-60 \mathrm{~g} / \mathrm{mL}$ for all cell lines tested $(B, D, F, H, J)$. 
The non-cancerous fibroblast control cell line, Hs27 (Fig. $1 \mathrm{E})$, demonstrated the ability to proliferate and spread in the presence of PAC at all concentrations (Fig. 1J). In addition, these cells did not exhibit characteristics of apoptosis; however, a reduction in the overall number of cells was evident at the higher concentration. This apparent inhibition of cellular proliferation was sustained and became more pronounced over time, although these effects on cell viability and cell spreading were less pronounced than for any of the other cell lines tested (Table $1)$.

\section{Proliferation}

Ca Ski (CC) and GH354 (CAC)

To quantitate our observation that the administration of PAC may inhibit the proliferation of these cancer cell lines, in addition to the possible induction of apoptosis, the cervical carcinoma cell lines, Ca Ski and GH354, were grown in 96-well assay plates and their proliferation was measured over four days in three separate, independent experiments. Our results demonstrated that PAC elicited selective responses in the Ca Ski (HPV 16-containing) and GH354 (HPV 18-containing) cell lines. Low dose administration of PAC stimulated Ca Ski proliferation, while higher doses were inhibitory in a dose-dependent manner. All doses of PAC were inhibitory in GH354 cells, although the level of inhibition was determined to be dose dependent.

More specifically, Ca Ski cell proliferation was initially stimulated by the administration of PAC at the concentration of $10 \mu \mathrm{g} / \mathrm{mL}(+5 \%)$, while higher doses, between $20-$ $100 \mu \mathrm{g} / \mathrm{mL}$, had an opposite, inhibitory effect on proliferation (Fig. 2A). To reduce the initial proliferation-stimu-

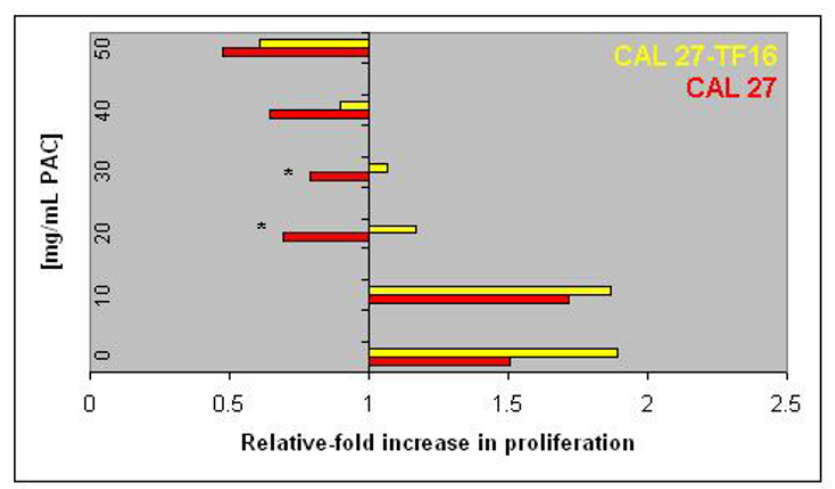

\section{Figure 3}

HPV 16 mediates the proliferation-inhibitory effects of PAC on OSCC. PAC dosage of $50 \mu \mathrm{g} / \mathrm{mL}$ was the $\mathrm{GI}_{\mathrm{MAX}}$ for both CAL 27 and CAL 27-TFI 6 cells. PAC doses greater than $20 \mu \mathrm{g} / \mathrm{mL}$ resulted in a net loss of cells in the CAL 27 assays, but was modulated by the presence of HPV 16 at dosages above $40 \mu \mathrm{g} / \mathrm{mL}$ in the CAL 27-TFI 6 assays. lating effects of trypsinizing and plating the cells into each assay, seen between day 0 and day 1 in most assays, we determined the relative change in proliferation between day 4 and day 1 (day 4 minus day 1). Our results demonstrated that the effects of PAC induced only a slight inhibition of cell proliferation between $10-20 \mu \mathrm{g} / \mathrm{mL}$, but induced a sharp decrease in proliferation extending over the range of $30-100 \mu \mathrm{g} / \mathrm{mL}$ with the maximal growth inhibitory dose $\left(\mathrm{GI}_{\mathrm{MAX}}\right)$ at $50 \mathrm{mg} / \mathrm{mL}$ (Fig. 2B).

The effects of PAC administration on GH354 cells produced slightly different proliferative responses compared with the effects on Ca Ski cell proliferation (Fig. 2C). For example, all doses of PAC tested inhibited GH354 proliferation. Although these results suggest that the lowest dose of PAC $(10 \mu \mathrm{g} / \mathrm{mL})$ had the smallest effect of inhibiting proliferation, an analysis of the relative change in proliferation revealed a more complicated interaction between PAC effects and GH354 proliferation (Fig. 2D). These results revealed that all doses of PAC tested were growth inhibitory; $\mathrm{GI}_{\mathrm{MAX}}$ was established at $30 \mu \mathrm{g} / \mathrm{mL}$, with higher doses exhibiting slightly less robust proliferation-inhibitory effects.

\section{Hs27 (hFF)}

A control cell line, Hs27, human foreskin fibroblasts, was also tested as described above. Our results demonstrated that Hs27 cells exhibited dose-dependent responses to PAC administration (Fig. 2I). $\mathrm{GI}_{\mathrm{MAX}}$ was determined to be $60 \mu \mathrm{g} / \mathrm{mL}$, which closely approximated the maximum inhibitory dosages observed for the other cell lines tested (Fig. 2J). As with Ca Ski and GH354 cell lines, no dosage of PAC resulted in a net loss of cells over the course of these assays.

\section{CAL 27 (OSCC) and CAL 27-TFI6 (OSCC)}

To test our hypothesis that PAC administration inhibits proliferation of OSCC, the OSCC cell line, CAL 27, was assayed and proliferation was measured over four days in three, separate independent experiments. Our results demonstrated that PAC induced variable responses, similar to the effects on Ca Ski cells, in a dose-dependent manner (Fig. 2E). The proliferation of CAL 27 cells was slightly increased by the lowest concentration of PAC $(10 \mu \mathrm{g} / \mathrm{mL})$, while increasing doses produced an inhibitory effect on proliferation over the range of $20-100 \mu \mathrm{g} / \mathrm{mL}$ (Fig. 2F). To determine the growth inhibitory dose, we analyzed the relative change in proliferation and found that PAC doses between $20-40 \mu \mathrm{g} / \mathrm{mL}$ exhibited increasing inhibitory effects on proliferation, $\mathrm{GI}_{\mathrm{MAX}}$ was determined to be 50 $\mu \mathrm{g} / \mathrm{mL}$, while larger doses, between $60-80 \mu \mathrm{g} / \mathrm{mL}$, displayed ever-diminishing inhibitory effects as the dose was increased. All PAC doses above $40 \mu \mathrm{g} / \mathrm{mL}$ resulted in a net loss of cells over the course of the assay. 


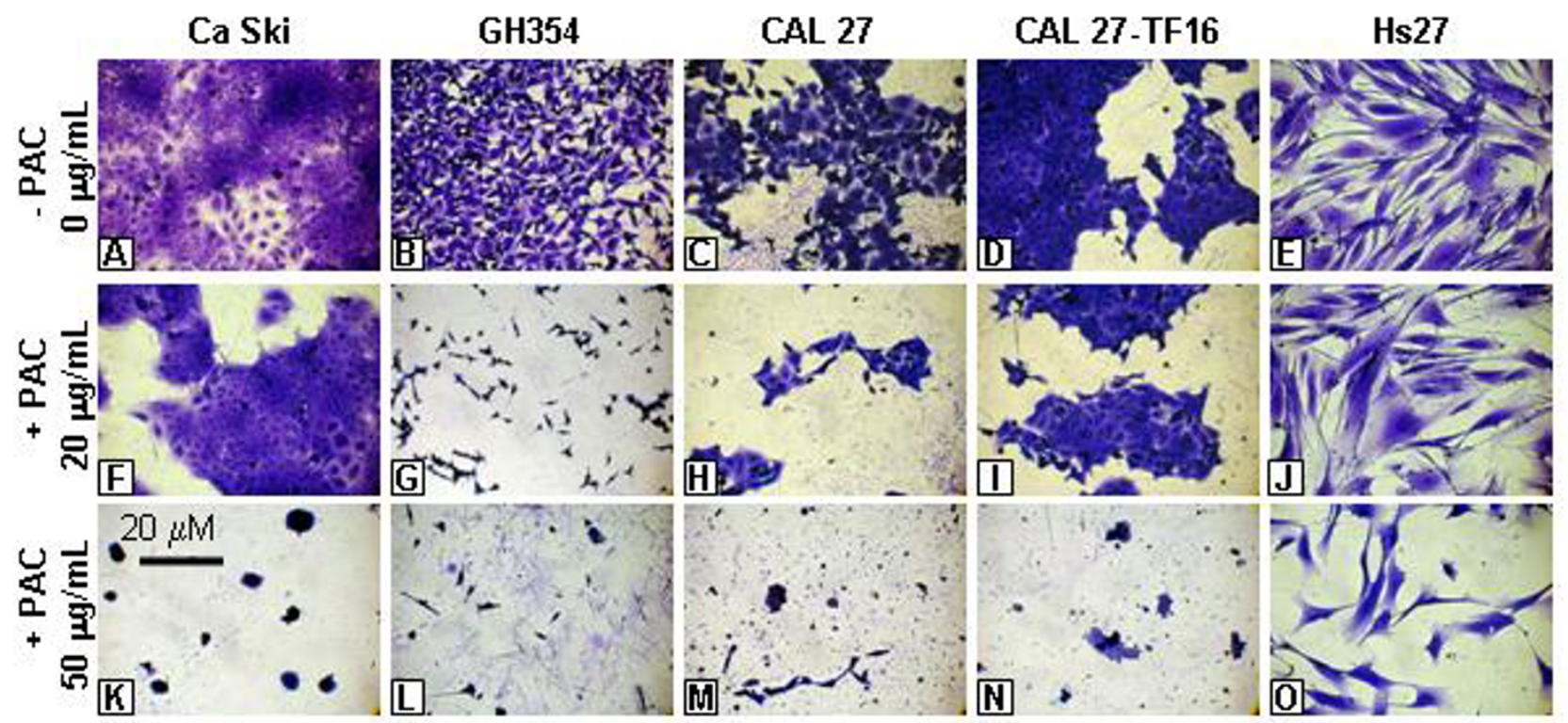

\section{Figure 4}

Dose-dependent effects of PAC on proliferation and morphology. Cells were plated in 96-well assay plates in media with FBS. The upper row (A-E) was grown without PAC, the mid-level row (F-J) in the presence of PAC at $20 \mu \mathrm{g} / \mathrm{mL}$, and the lower row (K-O) under PAC administration at $50 \mu \mathrm{g} / \mathrm{mL}$. All cell lines exhibited a dose-dependent response to PAC administration, with higher doses resulting in fewer cells at day 4. Ca Ski (A), CAL 27 (C), CAL 27-TFI6 (D) and Hs27 (E) cells were reduced in number with PAC at $20 \mu \mathrm{g} / \mathrm{mL}(\mathrm{F}, \mathrm{H}, \mathrm{I}, \mathrm{J})$, unlike $\mathrm{GH} 354$ cells (B), which experienced a reduction in proliferation, and morphological changes indicative of apoptosis $(\mathrm{G})$. Cellular proliferation was reduced by PAC in all cell lines (K-O) at 50 $\mu \mathrm{g} / \mathrm{mL}$; all cell lines exhibited altered morphology, except Hs27 (O) cells which appeared normal, although fewer in number.

Our previous studies with OSCC proliferation revealed that CAL 27 cells proliferated more rapidly after transfection with HPV 16 [27]. To contextualize our results from this current study, we assayed HPV 16-transfected CAL 27 cell proliferation under PAC administration over four days in three, separate independent experiments. Our results revealed that PAC induced dose-dependent effects, similar to the responses of CAL 27, with some notable differences (Fig. 2G). The proliferation of CAL 27-TF16 cells was increased by the two lowest concentrations of PAC $(10-20 \mu \mathrm{g} / \mathrm{mL})$, while further increasing doses produced inhibitory effects on proliferation within the range of 30$100 \mu \mathrm{g} / \mathrm{mL}$. $\mathrm{GI}_{\text {MAX }}$ was also determined to be $50 \mu \mathrm{g} / \mathrm{mL}$, with higher doses exhibiting no greater inhibitory effects than at $\mathrm{GI}_{\mathrm{MAX}}$ (Fig. 2H). The maximal inhibitory PAC dose of $50 \mu \mathrm{g} / \mathrm{mL}$ resulted in a net loss of these cells over the course of the assay.

To clearly delineate the results of our proliferation assays for CAL 27 and CAL 27-TF16, cells were plated in the presence of PAC dosages between 0 and $\mathrm{GI}_{\mathrm{MAX}}(50 \mu \mathrm{g} / \mathrm{mL})$. Confirming our previous observations, PAC administration once again stimulated CAL 27 cells at the lowest concentration tested $(10 \mu \mathrm{g} / \mathrm{mL})$, but higher concentrations inhibited proliferation (Fig. 3). All concentrations above
$20 \mu \mathrm{g} / \mathrm{mL}$ resulted in a net loss of cells, with the $\mathrm{GI}_{\mathrm{MAX}}$ observed at $50 \mu \mathrm{g} / \mathrm{mL}$, demonstrating a net loss of more than $50 \%$ of the original number of cells plated at day 0 . PAC administration also stimulated CAL 27-TF16 cells at low concentrations $(10 \mu \mathrm{g} / \mathrm{mL})$, but higher concentrations induced reduced levels of proliferation. One disparate result was that PAC administration between 20-30 $\mu \mathrm{g} / \mathrm{mL}$ inhibited CAL 27-TF16 cells, unlike the non-transfected CAL 27 cells, without precipitating a net loss of cells. However, PAC dosages above $40 \mu \mathrm{g} / \mathrm{mL}$ did result in a net loss of cells with $\mathrm{GI}_{\mathrm{MAX}}$ determined in this assay to be $50 \mu \mathrm{g} / \mathrm{mL}$.

\section{Dose-dependent cell morphology responses}

Even though we have described the dose-dependent inhibition of cellular proliferation in response to PAC administration through in vitro cell culture assays, we wished to clarify the effects of PAC administration on cell morphology at dosages that may provide the most information about the nature and timing of possible apoptosis events (Fig. 4). We first examined cell growth in all cell lines in the absence of PAC for comparison (Fig. 4A-E).

Inhibition of proliferation was induced by treatment of cells with low concentrations of PAC, sustained over time 
A

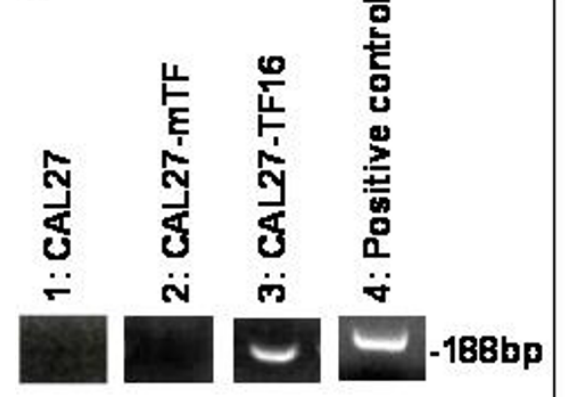

B

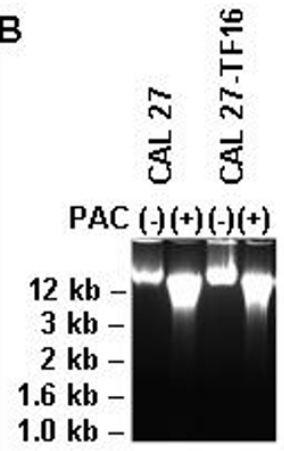

Figure 5

Total RNA and DNA analysis of CAL 27 cells. RT-PCR performed on total RNA extracted from OSCC, CAL 27, revealed that CAL 27 did not express HPV 16-specific mRNA (A: Lane I). Mock transfectants (A: Lane 2) also did not express HPV. HPV I6-transfected cells (A: Lane 3) expressed HPV 16; specific primers were tested using PCR and the full-length HPV I6-DNA template (A: Lane 4). Total DNA isolated from CAL 27 cells (B: Lane I) and CAL 27TFI 6 cells (B: Lane 3 ) demonstrated DNA alterations following PAC treatment $(50 \mu \mathrm{g} / \mathrm{mL})$, including a more diffuse banding pattern and lower molecular weight, possibly indicating the onset of DNA fragmentation among the treated cells (B: Lane 2, 4).

(Fig. 4F-J). In examining the cervical carcinoma cell lines, Ca Ski and GH354, we observed that cell number was reduced in Ca Ski cultures (Fig. 4F), but that both morphology and cell number were altered in GH354 cells (Fig. 4G) at low PAC concentration $(20 \mu \mathrm{g} / \mathrm{mL})$. The same concentration of PAC reduced the overall number of $\mathrm{Hs} 27$ cells, without inducing demonstrable changes in cell morphology (Fig. 4J). The OSCC cell lines, CAL 27 (Fig. 4H) and CAL 27-TF16 (Fig. 4I), also exhibited reduced proliferation in response to this PAC concentration, but exhibited no specific evidence of apoptotic events.

Higher concentrations of PAC, on the other hand, elicited different responses in cell morphology and appearance. Cell clustering and rounding was induced in all cancer cell lines (K-N) with PAC $(50 \mu \mathrm{g} / \mathrm{mL})$. Possible evidence of apoptosis at this concentration was first observed in all cell lines, except Hs27 (Fig. 4O), between 18 and 24 hours, and was observed as a relatively slow event that resulted in a rounding of cells together followed by intense surface blebbing. Surface blebbing continued from day 1 to day 4 until more active blistering and lytic events resulted in the net loss of cells in each assay.

The cervical carcinoma cell line, Ca Ski (Fig. 4F), and HPV16-transfected OSCC cell line, CAL 27-TF16 (Fig. 4I), were more resistant to lysis and cell death at the lower PAC concentration $(20 \mu \mathrm{g} / \mathrm{mL})$ and appeared to be

rounded and blebbing at day 4 , while the majority of GH354 cells (Fig. 4G) and non-transfected CAL 27 cells (Fig. 4H) may have already undergone these transformations. The higher PAC concentration $(50 \mu \mathrm{g} / \mathrm{mL}$ approximating $\mathrm{GI}_{\mathrm{MAX}}$ ) further reduced absolute cell number and induced these morphologic changes in all cell lines (Fig. $4 \mathrm{~K}-\mathrm{N}$ ), except Hs27 cells which exhibited no evidence suggesting apoptotic changes (Fig. 4O).

\section{Nucleic acid analysis}

To confirm that the CAL 27 cells used in this study did not harbor HPV 16 prior to transfection, we performed RTPCR on total RNA isolated from cultured CAL 27 cells used for these experiments and oligonucleotide primers specific for the HPV 16 strain (Fig. 5A). Our results demonstrated that neither CAL 27 cells (Lane 1) nor CAL 27 mock-transfected cells (Lane 2) expressed HPV 16 mRNA prior to transfection. After completing transient transfection of CAL 27 with HPV 16, our results confirmed that CAL 27-TF16 cells expressed HPV 16-specific mRNA (Lane 3). HPV 16-specific primers were tested using PCR and the HPV 16 DNA template (Lane 4) to confirm the band size and specificity of the primers to the template.

The administration of PAC had multiple effects, including a dose-dependent reduction in cellular proliferation and changes in cellular morphology among cancer cell lines. This study also assessed total DNA isolated from CAL 27 and CAL 27-TF16 cells in the absence and presence of PAC at $50 \mu \mathrm{g} / \mathrm{mL}$ (Fig. 5B), revealing that PAC administration induced some alteration and fragmentation of total DNA, resulting in a more diffuse and less compact banding pattern. In addition, PAC administration reduced the overall molecular weight of the chromosomal DNA extracted, which may represent one stage in the process of DNA fragmentation, characteristic of cells undergoing necrosis or apoptosis.

\section{Discussion}

Proanthocyanidins are part of a larger group of compounds that have been demonstrated to have anti-proliferative and anti-tumor effects $[13,26,33]$. PAC can be isolated from multiple sources and the therapeutic benefits of PAC may be determined, in part, by the fruit or vegetable from which it is derived [34]. GSE and other fruitderived flavonoid extracts have demonstrated robust antiproliferative effects on other oral and epithelial cancers $[17,24,35,36]$.

Although other studies have demonstrated that particular fractions of GSE or raspberry extracts may be cytotoxic against oral tumor cell lines, none have yet examined PAC specifically to analyze its effects on oral cancer proliferation. Through this study, we have demonstrated that PAC exhibited dose-dependent inhibitory and cytotoxic effects 
on cervical cancer cell lines, with these effects more selective and intensely specific for OSCC. In addition, HPV, now believed to initiate oral cancers among non-smokers, and to modulate OSCC proliferation and progression among smokers, was modulated and reduced, in a dosedependent manner, by the administration of PAC.

A closer examination of PAC administration among these various cell lines revealed that the effects of PAC were less intense and more gradual in the foreskin and cervical cancer cell lines, Hs27 and Ca Ski, respectively. In contrast, at even the lowest dosages, PAC substantially inhibited the proliferation of both the cervical cancer cell line, GH354, and the OSCC cell line, CAL 27. Furthermore, the level of inhibition was dissimilar between these two cancers only limiting proliferation of the cervical cell line, GH354, but resulting in a net loss of cells in the oral cancer line, CAL 27. This level of cytotoxicity may represent a selective effect which suggests that OSCC may be rendered more susceptible to this treatment.

Although we found that PAC exhibited a general inhibitory effect on all cell lines tested, a morphological change was observed after PAC administration in both the cervical and oral cancer cell lines that suggested the possible induction of apoptosis. Images obtained from live cell cultures under PAC administration demonstrated that many of the cells were clustering, rounding, and blebbing - morphologic changes that are often suggestive of apoptosis. However, once the cells were fixed and stained to quantify these effects on proliferation, only Ca Ski cells and non-cancerous controls Hs27 were sufficiently adhered to remain in the assay plates at the $\mathrm{GI}_{\mathrm{MAX}}$ concentration of PAC. One possible reason for this phenomenon may be the degree of progression toward apoptosis or cell death; the more susceptible cell lines, such as GH354, CAL 27, and CAL 27-TF16, could be further along the apoptotic pathway and therefore less capable of adhering and more likely to be removed by mechanical forces during the fixation and staining process. The DNA analysis revealed fragmentation, but no banding patterns indicative of internucleosomal cleavage, suggesting further experimentation will be necessary to delineate the pathways and mechanisms associated with these changes.

Aside from demonstrating that PAC may exhibit differential effects among different cancers, we found convincing evidence that HPV may modulate, and in turn be modulated by, the effects of PAC with respect to the OSCC proliferative response. Our previous research found that HPV 16 strongly induced OSCC proliferation and our findings here indicate that HPV 16 also influenced OSCC response under PAC administration. The introduction of HPV 16 into these cells not only increased their relative levels of proliferation, but also mediated their response to PAC, with lower dosages actually stimulating proliferation of CAL 27-TF16 cells. Interestingly, the $\mathrm{GI}_{\mathrm{MAX}}$ was determined to be invariable for both transfected and nontransfected cells, suggesting that despite this modulating effect, the HPV 16-specific effect was not sufficient to alter OSCC proliferation in response to incremental increases of PAC administration at or beyond $\mathrm{GI}_{\mathrm{MAX}}$.

One critical goal of cancer treatment is to find chemopreventive and therapeutic agents that selectively target cancer cells without detrimental effects to healthy cells and tissues. Although many chemotherapeutic agents are currently being used in the treatment of oral cancers, such as cisplatin (CDDP) and 5-fluorouracil (5-FU), it is known that most tumors may be more or less resistant to these drug therapies because they are not dependent on a single receptor or signal transduction pathway for growth and progression [5]. Thus, compounds or combinations of compounds that may activate multiple apoptotic pathways, such as PACs, may provide new and more effective treatment regimens for patients with oral cancer.

Recent studies have determined that PACs can be administered orally as a dietary supplement and are subsequently bioavailable, in both serum and tissues at $\mu \mathrm{g} / \mathrm{mL}$ concentrations, without any significant toxicity, implying that PACs may represent one class of promising candidates for use as an adjuvant therapeutic agent in patients receiving chemotherapy for oral cancer $[37,38]$. The supporting evidence that GSE and other flavonoid extracts are effective as adjuvants and treatments for breast, colon, and prostate cancer, combined with the results of this study, demonstrate that PAC may act even more selectively on OSCC than other cell lines. This suggests the possibility that PACs may act synergistically to induce selective inhibition and apoptosis of oral cancers in vivo.

\section{Conclusion}

PAC-containing commercial products, such as ActiVin ${ }^{\circledast}$, OptiBerry $^{\circledast}$, Grape Seed Proanthocyanidin Extract, and others, have been verified as well-tolerated and non-toxic $[33,34,39]$. However, due to incomplete information regarding alternative and combination therapies, we advocate here for systematic animal, and subsequently human chemoprevention trials, to confirm that PAC may suppress tumor proliferation or induce tumor apoptosis, without eliciting deleterious effects on viability and growth of normal tissue. This study provides convincing evidence that PAC administration is sufficient to reduce OSCC proliferation in vitro and that it may also effectively modulate the proliferation-enhancing effects of concomitant HPV infection. Consequently, if these effects can be substantiated, it will then become vital to decipher which of the signalling pathways PAC may influence in OSCC, including the possible inhibition of MAPK (mitogen acti- 
vated protein kinase), ODC (ornithine decarboxylase), EGFR (epidermal growth factor receptor), or caspasedependent pathways.

\section{Competing interests}

The author(s) declare that they have no competing interests.

\section{Authors' contributions}

KK and SO conceived, monitored and coordinated the experimental design. SO, MK, KC, DF, DJ, JP and AS carried out the transfection, cell culture, and proliferation assays. Both KK and SO contributed equally to the writing of this manuscript. All authors have read and approved the final manuscript.

\section{Acknowledgements}

This research was supported, in part, by an Institutional Research Grant (IRG) from the American Cancer Society (ACS) to KK (ACS-IRG\# 103719). KK and SO are especially grateful to G Galbraith and the Department of Biomedical Sciences at the UNLV School of Dental Medicine for additional support and also to $\mathrm{K}$ Howard for her assistance. KK would also like to thank $M$ Keiserman for special assistance and patience during the preparation of this manuscript.

\section{References}

I. Davies L, Welch HG: Epidemiology of head and neck cancer in the United States. Otolaryngol Head Neck Surg 2006, I35:45 I-457.

2. Ragin CCR, Modugno F, Gollin SM: The epidemiology and risk factors of head and neck cancer: a focus on human papillomavirus. J Dent Res 2007, 86: 104-II4.

3. Miller CS, Johnstone BM: Human papillomavirus as a risk factor for oral squamous cell carcinoma: A meta-analysis, 19821997. Oral Surg Oral Med Oral Pathol 2001, 91:622-635.

4. Le Marchand L: Cancer preventive effects of flavonoids-a review. Biomed Pharmacother 2002, 56:296-301.

5. Hsu S, Singh B, Schuster G: Induction of apoptosis in oral cancer cells: agents and mechanisms for potential therapy and prevention. Oral Oncol 2004, 40:461-473.

6. Pavia M, Pileggi C, Nobile CGA, Angelillo IF: Association between fruit and vegetable consumption and oral cancer: a metaanalysis of observational studies. Am J Clin Nutr 2006, 83: I I26-II34.

7. de Pascual-Teresa S, Santos-Buelga C, Rivas-Gonzalo JC: Quantitative analysis of flavan-3-ols in Spanish foodstuffs and beverages. J Agric Food Chem 2000, 48:533I-5337.

8. Gu L, Kelm M, Hammerstone JF, Beecher G, Cunningham D, Vannozzi S, Prior RL: Fractionation of polymeric procyanidins from lowbush blueberry and quantification of procyanidins in selected foods with an optimized normal-phase HPLC-MS fluorescent detection method. J Agric Food Chem 2002, 50:4852-4860.

9. Gu L, Kelm MA, Hammerstone JF, Beecher G, Holden J, Haytowitz D, Gebhardt S, Prior RL: Concentrations of proanthocyanidins in common foods and estimations of normal consumption. J Nutr 2004, 134:613-617.

10. Ricardo da Silva JM, Cheynier V, Sansom A, Bourziex M: Effect of pomace contact, carbonic maceration, and hypoeroxidation on the procyanidin composition of Grenache blanc wines. Am J Enol Vitic 1993, 44:168-172.

II. Bagchi D, Bagchi M, Stohs SJ, Das DK, Ray SD, Kuszynski CA, Joshi SS, Pruess HG: Free radicals and grape seed proanthocyanidin extract: importance in human health and disease prevention. Toxicology 2000, I48: I87-197.

12. Kim H, Hall P, Smith M, Kirk M, Prasain JK, Barnes S, Grubbs C: Chemoprevention by grape seed extract and genistein in carcinogen-induced mammary cancer in rats is diet dependent. J Nutr 2004, 134:3445S-3452S.
13. Seeram NP, Adams LS, Hardy ML, Heber D: Total cranberry extract versus its phytochemical constituents: antiproliferative and synergistic effects against human tumor cell lines. J Agric Food Chem 2004, 52:25I 2-25I7.

14. Vayalil PK, Mittal A, Kativar SK: Proanthocyanidins from grape seeds inhibit expression of matrix metalloproteinases in human prostate carcinoma cells, which is associated with the inhibition of MAPK and NF kappa B. Carcinogenesis 2004, 25:987-995.

15. Hong H, Yi-Min Q: Grape seed proanthocyanidin extract induced mitochondria-associated apoptosis in human acute myeloid leukaemia I4.3DIO cells. Chinese Med I 2006, I I 9:4|7-42I.

16. Shirataki Y, Kawase M, Saito S, Hurihara T, Tanaka W, Satoh K, Sakagami H, Motohashi N: Selective cytotoxic activity of grape peel and seed extracts against oral tumor cell lines. Anticancer Res 2000, 20:423-426.

17. Rodrigo KA, Rawal Y, Renner RJ, Schwartz SJ, Tian Q, Larsen PE, Mallery SR: Suppression of the tumorigenic phenotype in human oral squamous cell carcinoma cells by an ethanol extract derived from freeze-dried black raspberries. Nutr Cancer 2006, 54:58-68.

18. Kaur M, Singh RP, Gu M, Agarwal R, Agarwal C: Grape seed extract inhibits in vitro and in vivo growth of human colorectal carcinoma cells. Clin Cancer Res 2006, 12:6194-6202.

19. Tyagi A, Agarwal R, Agarwal C: Grape seed extract inhibits EGFinduced and constitutively active mitogenic signaling but activates JNK in human prostate carcinoma DUI45 cells: possiblerole in antiproliferation and apoptosis. Oncogene 2003, 22:1302-1316.

20. Katiyar SK: Matrix metalloproteinases in cancer metastasis: molecular targets for prostate cancer prevention by green tea polyphenols and grape seed proanthocyanidins. Endocr Metab Immune Disord Drug Targets 2006, 6: 17-24.

21. Matchett MD, MacKinnon SL, Sweeney MI, Gottschall-Pass KT, Hurta RAR: Inhibition of matrix metalloproteinase activity in DUI45 human prostate cancer cells by flavonoids from lowbush blueberry (Vaccinium angustifolium): possible roles for protein kinase $C$ and mitogen-activated protein-kinasemediated events. J Nutrl Biochem 2006, I7: I 17- 25.

22. Aruoma OI, Sun B, Fujii H, Neergheen VS, Bahorun T, Kang KS, Sung MK: Low molecular proanthocyanidin dietary biofactor Oligonol: Its modulation of oxidative stress, bioefficacy, neuroprotection, food application and chemoprevention potentials. Biofactors 2006, 27:245-265.

23. Kijima I, Phung S, Hur G, Kwok SL, Chen S: Grape seed extract is an aromatase inhibitor and a supressor of aromatase expression. Cancer Res 2006, 66:5960-5967.

24. Sakagami H, Jiang Y, Kusama K, Atsumi T, Ueha T, Toguchi M, Iwakura I, Satoh K, Fukai T, Nomura T: Induction of apoptosis by flavones, flavonols (3-hydroxyflavones) and isoprenoid-substituted flavonoids in human oral tumor cell lines. Anticancer Res 2000, 20:27I-277.

25. Kandil Fe, Smith MAL, Rogers RB, Pepin MF, Song LL, Pezzuto JM, Seigler DS: Composition of a chemopreventive proantho-cyaninrich fraction from cranberry fruits responsible for the inhibition of TPA-induced ODC activity. J Agric Food Chem 2002, 50:1063-1069.

26. Neto CC: Cranberry and its phytochemicals: $A$ review of in vitro anticancer studies. J Nutr 2007, 137:186S-193S.

27. Kingsley K, Johnson D, O'Malley S: Transfection of oral squamous cell carcinoma with human papillomavirus- 16 induces proliferative and morphological changes independent of cellular adhesion in vitro. Cancer Cell Int 2006, 6:14.

28. Bagchi M, Kuszynski CA, Balmoori J, Joshi SS, Stohs SJ, Bagchi D: Protective effects of antioxidants against smokeless tobaccoinduced oxidative stress and modulation of $\mathrm{bcl}-2$ and $\mathrm{p53}$ genes in human oral keratinocytes. Free Rad Res 200I, 35: $181-194$.

29. Sano T, Oda E, Yamashita T, Naemura A, ljiri Y, Yamakoshi J, Yamamota J: Anti-thrombotic effect of proanthocyanidin, a purified ingredient of grape seed. Thromb Res 2005, II5:II5-I2I.

30. Felsher DW, Zetterberg A, Zhu J, Tisty T, Bishop JM: Overexpression of MYC causes p53-dependent $G 2$ arrest of normal fibroblasts. Proc Natl Acad Sci USA 2000, 97: $10544-10548$. 
31. Kingsley K, Huff JL, Rust WL, Carroll K, Martinez AM, Fitchmun M, Plopper GE: ERK I/2 mediates PDGF-BB stimulated vascular smooth muscle cell proliferation and migration on laminin5. Biochem Biophys Res Commun 2002, 293:1000-1006.

32. Hays WL: Inferences about population means. In Statistics 5th edition. International Thomson Publishing; 1994:3 I I-342.

33. Bagchi $D$, Sen CK, Bagchi M, Atalay M: Anti-angiogenic, antioxidant, and anti-carcinogenic properties of a novel anthocyanidin-rich berry extract formula. Biochemistry 2004, 69:75-80.

34. Park EJ, Pezzuto JM: Botanicals in cancer chemoprevention. Cancer Metastasis Rev 2002, 21:231-255.

35. Bagchi D, Bagchi M, Stohs S, Ray SD, Sen CK, Preuss HG: Cellular protection with proanthocyanidins derived from grape seeds. Ann NY Acad Sci 2002, 957:260-270.

36. Bagchi D, Roy S, Patel V, He G, Khanna S, Ojha N, Phillips C, Ghosh $S$, Bagchi M, Sen CK: Safety and whole-body antioxidant potential of a novel anthocyanin-rich formulation of edible berries. Mol Cell Biochem 2006, 28I:197-209.

37. Sano A, Yamakoshi J, Tokutake S, Tobe K, Kubota Y, Kikuchi M: Procyanidin $B I$ is detected in human serum after intake of proanthocyanidin-rich grape seed extract. Biosci Biotechnol Biochem 2003, 67: II40-1 I43.

38. Manach C, Williamson G, Morand C, Scalbert A, Remesy C: Bioavailability and bioefficacy of polyphenols in humans. I. Review of 97 bioavailability studies. Am J Clin Nutr 2005, 8I:230S-242S

39. Bagchi D, Sen CK, Ray SD, Das DK, Bagchi M, Press HG, Vinson JA: Molecular mechanisms of cardioprotection by a novel grape seed proanthocyanidin extract. Mutat Res 2003, 523-524:87-97.

\section{Pre-publication history}

The pre-publication history for this paper can be accessed here:

http://www.biomedcentral.com/1472-6882/7/22/prepub

Publish with Bio Med Central and every scientist can read your work free of charge

"BioMed Central will be the most significant development for disseminating the results of biomedical research in our lifetime. "

Sir Paul Nurse, Cancer Research UK

Your research papers will be:

- available free of charge to the entire biomedical community

- peer reviewed and published immediately upon acceptance

- cited in PubMed and archived on PubMed Central

- yours - you keep the copyright
BioMedcentral 